\title{
CARACTERIZAÇÃO E ANÁLISE QUALI-QUANTITATIVA DA ARBORIZAÇÃO EM PRAÇAS DA ÁREA CENTRAL DA CIDADE DE ARAPIRACA, AL ${ }^{1}$
}

\author{
Rosineide Nascimento da Silva ${ }^{2} 3$
}

\section{RESUMO}

Nas cidades, a arborização se apresenta como uma importante problemática ${ }^{4}$ relacionada com o conforto humano e questões de responsabilidade ambiental, por exemplo. Este estudo caracterizou e analisou a arborização das três principais praças do centro da cidade de Arapiraca, Alagoas, observando as espécies que ocorrem, a quantidade de árvores e sua fitossanidade. Foram realizadas visitas de campo; aplicação de formulário quali-quantitativo; coleta de material; preenchimento de ficha de coleta e produção fotográfica. Das 65 árvores contabilizadas, as espécies mais frequentes foram Pachira aquatica Aubl., Erythrina indica Lam. e Schinus terebinthifolia Raddi. As famílias mais frequentes foram Malvaceae (27,7\%), Fabaceae (26,2\%) e Arecaceae (15,4\%). As árvores foram consideradas, fitossanitariamente, insatisfatórias devido à fitopatógenos, sofrem com a prática de podas, conflitam com equipamentos urbanos e são alvos de injúrias/agressões mecânicas. Espera-se que tais resultados possam orientar as políticas públicas na criação de um Plano de Manejo da Arborização em Arapiraca.

Palavras-chave: Árvores urbanas; Espaços públicos; Fitossanidade; Planejamento urbano ambiental

\section{CHARACTERIZATION AND QUALI-QUANTITATIVE ANALYSIS OF ARBORIZATION IN SQUARES OF THE CENTRAL AREA OF THE CITY OF ARAPIRACA, ALAGOAS}

\section{ABSTRACT}

In the cities, the arborization present as an important problem related to the human comfort and subjects of environmental responsibility, for example. This study characterized and analyzed the arborization of the three main squares of the city of Arapiraca, Alagoas, observing the species that happen, the amount of trees and their phytossanit. Bibliographical consultations were accomplished; field visits; application of quali-quantitative form; collection of material; filling in of the record of collection and photographic production. Of the 65 trees counted, the most frequent species were Pachira aquatica Aubl., Erythrina indica Lam. and Schinus terebinthifolia Raddi. The most frequent families were Malvaceae $(27,7 \%)$, Fabaceae (26,2\%) and Arecaceae (15,4\%). The trees were considered, phytosanitary, unsatisfactory due to phytopathogenic, suffer with the practice of prunings, conflict with urban equipments and are object of mechanical offense/aggression. It is waited that such results can guide the public politics in the creation of a Plan of Handling of Arborization in Arapiraca.

Keywords: Urban trees; Public spaces; Phytossanitary; Planning urban environmental

\footnotetext{
${ }^{1 .}$ Este artigo é parte do Trabalho de Conclusão do Curso de Biologia - Licenciatura, orientado pelo Prof. Dr. Marcos Antônio Silvestre Gomes da Universidade Federal Fluminense.

2. Licenciada em Biologia. Universidade Federal de Alagoas - Campus Arapiraca. Av. Manoel Severino Barbosa, s/n, Bom Sucesso, Caixa Postal 61. Rodovia AL 115 - Km 6,5. Arapiraca - AL. CEP: 57309-005. E-mail: rosineideg7@gmail.com.

${ }^{3}$ (recebido em 28.07.2011 e aceito para publicação em 15.06.2012)

4. Este termo está sendo usado neste trabalho, como o faz Rodrigues (2005), para designar um conjunto de problemas entrelaçados entre si e não apenas um problema isolado. Neste caso, em específico, trata-se da arborização urbana não como um problema a ser enfrentado nas cidades, mas como um elemento presente no espaço que se relaciona a fatores ambientais, sociais, políticos, etc.
} 


\section{INTRODUÇÃO}

Diante das análises e debates que buscam contribuir com a melhoria das condições ambientais nas cidades, as discussões acerca da arborização torna-se uma questão importante, sobretudo quando se trata de praças, parques e outros espaços de uso coletivo necessários aos centros urbanos.

No caso das praças, ênfase deste estudo, estas representam para as cidades, em geral, um dos locais mais populares que proporcionam momentos de lazer/recreação, contemplação da paisagem ou de elementos da natureza, convívio social, etc.

Para Silva (2009), as praças são locais representativos para distintas manifestações ao permitir a formação e agregação sociais. Não obstante, a gênese das praças está atrelada à história das cidades, tornando-se um dos espaços públicos mais comuns em diversas regiões, independentemente dessas apresentarem diferenças sociais, políticas, econômicas ou ambientais. Em síntese, é um importante espaço devido a muitos fatores, sejam estes relativos ao lazer como aos aspectos ecológicos, sociais, políticos ou educativos.

Nesse sentido, a arborização destes locais tem surgido como uma das problemáticas urbanas mais representativas, concebida como apenas mais uma infraestrutura urbana, (TARNOWSKI; MOURA, 1991) ou simplesmente esquecida pelas políticas de planejamento das cidades. A arborização passou a integrar discussões que envolvem as concepções de conservação e educação ambientais.

Uma das primeiras problemáticas porque perpassa a questão da arborização refere-se à sua conceituação, muito discutida na literatura. Neste trabalho, o conceito de arborização adotado é aquele que se refere à vegetação adulta de porte arbóreo (LIMA et al., 1994), situada em espaços públicos que integram as áreas verdes urbanas. Esta definição assemelha-se à concepção de Rocha e Werlang (2005), que defendem a ideia de que a arborização urbana caracteriza-se pelo plantio de árvores de porte em determinados locais da cidade.
Acredita-se que a concepção de arborização nas cidades assume um caráter cada vez mais confuso devido a ausência de uma definição clara e objetiva, o que dificulta determinadas ações de melhoria e otimização de seus benefícios.

Nas cidades, a vegetação é concebida como um elemento que pode desempenhar uma série de funções, como proteger o solo, a água, o ar; atenuar a temperatura e o clima; abrigar a fauna citadina; proporcionar condições de lazer/recreação e valorizar determinadas parcelas do solo urbano, conforme relatam os estudos de Gomes e Amorim (2003), Nucci (2001), Silva (2009), Fernandes (2008), Rezende e Santos (2010), Cavalheiro e Del Picchia (1992), Brun et al. (2007), Yamamoto et al. (2004), etc.

Em cidades tropicais de clima quente, como é o caso de Arapiraca-AL, torna-se justificável a necessidade de uma arborização urbana que procure contribuir com as condições climáticas e edáficas do seu interior. Cada cidade tem clima próprio e tipo de solo característico, o que torna necessário a escolha de espécies arbóreas adequadas a essas condições para que possam promover seus potenciais benefícios. Além disso, necessitam de cuidados periódicos evitando-se, por exemplo, a introdução e proliferação de agentes fitopagênicos; a prática de ações prejudiciais, como podas inadequadas; conflitos com equipamentos urbanos e impactos mecânicos. A esse respeito, Miranda e Carvalho (2009) afirmam que os impasses sofridos pela arborização nas cidades podem ser justificados pela ausência de informações e técnicos especializados.

Com a revisão de literatura, foi possível perceber que é comum estudos que abordem a arborização viária, no entanto, ainda se notam poucos estudos que tratem da arborização encontrada em espaços de uso coletivo, como praças ou parques. Por isso, este estudo teve como objetivos caracterizar e analisar quali-quantitativamente a arborização das Praças Luiz Pereira Lima, Deputado Marques da Silva e Manoel André, situadas na área

CARACTERIZAÇÃO E ANÁLISE QUALI-QUANTITATIVA... 
central da cidade de Arapiraca-AL. A hipótese era de que a arborização nestas praças era composta em sua maior parte por espécies exóticas, apressentassem baixa diversidade e quantidade, além de problemas fitosanitários que comprometessem a estrutura das mesmas. No entanto, os resultados mostraram-se complexos, evidenciando tanto diferenças quanto semelhanças importantes entre as praças, a diversidade de suas árvores e o estado em que se encontram.

Considerando-se que o município se caracteriza por uma deficiência generalizada de arborização, de acordo com levantamento efetuado pelo Dossiê Urbano Habitacional e Ambiental de Arapiraca (PREFEITURA MUNICIPAL DE ARAPIRACA, 2004), as praças analisadas se apresentam como locais relevantes na dinâmica da cidade por serem espaços com significativa cobertura vegetal. Este fato pode ser justificado por meio de seus significados para a população local, pela localização estratégica que permite apropriação dos seus usos e imagens para diferentes atores sociais, e pelas potencialidades que as praças apresentam, como aquelas relacionadas à arborização.

\section{MATERIAIS E MÉTODOS}

\section{Caracterização da área de estudo}

O município de Arapiraca, situado na região agreste e na parte central do Estado de Alagoas (Figura 1), ocupa uma área de cerca de 351,48 $\mathrm{Km}^{2}$ e possui 214.067 habitantes, sendo 181.562 residentes na zona urbana (IBGE, 2010a), o que resulta em densidade demográfica de 609,04 hab./Km². O Dossiê Urbano Habitacional e Ambiental de

\section{Arapiraca (PREFEITURA MUNICIPAL DE}

ARAPIRACA, 2004) informa que o município possui altitude de 264 m, está a 136 km de Maceió (capital do Estado) e possui as seguintes coordenadas geográficas: Latitude Sul 975’25” e Longitude Oeste 3660’11”.

Figura 1. Localização geográfica do município de Arapiraca no Estado de Alagoas

Figure 1. Geographical localization of Arapiraca municipality in Alagoas State

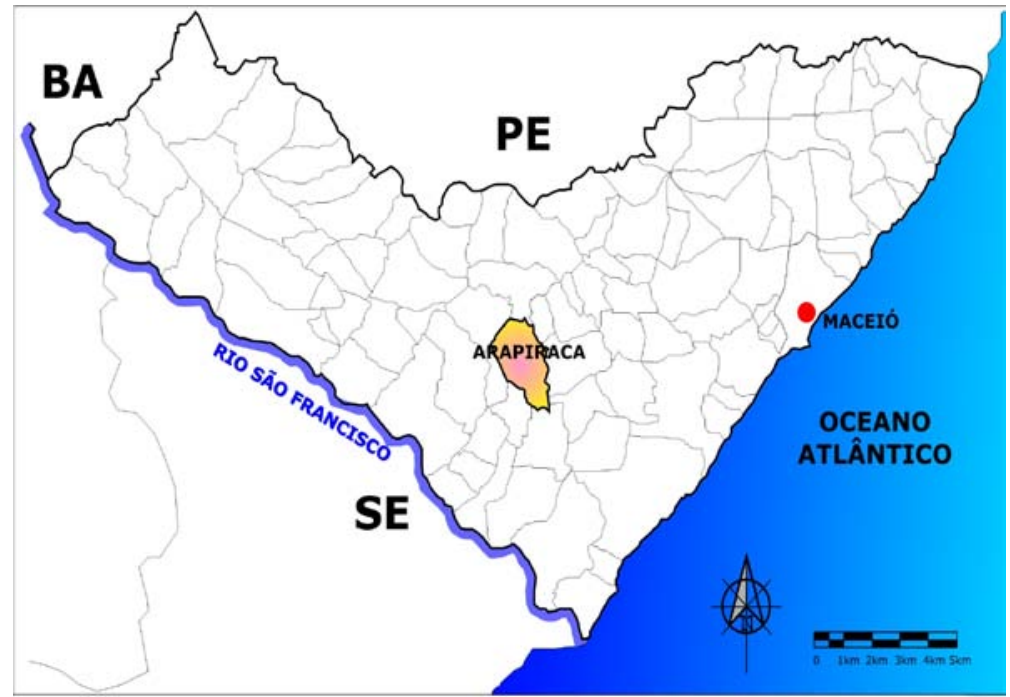

Fonte: Secretaria do Estado de Alagoas de Recursos Hídricos e Irrigação (2002). Extraída do Relatório das Características Ambientais de Arapiraca (PREFEITURA MUNICIPAL DE ARAPIRACA, 2006). Autor: Antônio R. N. Júnior 
A vegetação do município de Arapiraca se caracteriza por Floresta Subperenifólia, com partes de Floresta Subcaducifólia e cerrado/floresta (MASCARENHAS et al., 2005 ). Romão (2008) afirma que a vegetação natural do município, representada por áreas de Cerrado, Caatinga e Florestas Ombrófila ou Decidual foi praticamente erradicada, restando somente algumas árvores distribuídas pelas áreas de transição da Mata Atlântica e da Caatinga.

Mascarenhas et al. (2005) ainda relatam que o relevo de Arapiraca faz parte da unidade dos Tabuleiros Costeiros, com altitude média de 50 a $100 \mathrm{~m}$. De modo geral, os solos são classificados como profundos e de baixa fertilidade natural.

No Plano Diretor Participativo do Município (PREFEITURA MUNICIPAL DE ARAPIRACA, 2005), Arapiraca é caracterizada por temperaturas elevadas no verão, com média anual de $28^{\circ} \mathrm{C}$. Segundo Amorim (2005), a precipitação pluviométrica anual está entre 800 e $1000 \mathrm{~mm}$, o que resulta em um clima subúmido ou tropical quente.

Como município mais importante do interior do Estado de Alagoas, Arapiraca possui como base econômica uma produção agrícola diversificada, representada pelo cultivo de frutas, legumes e, principalmente, hortaliças. Esta nova base econômica surgiu a partir do declínio do cultivo histórico da monocultura do fumo entre os anos de 1980 e 1990, que contribuiu nas décadas anteriores para que o município fosse conhecido no cenário nacional como "capital brasileira do fumo". A fumicultura praticada ao longo de anos favoreceu a redução da cobertura vegetal de Arapiraca.

Na malha urbana há uma deficiência arbórea generalizada, podendo variar entre 83 e $100 \%$, conforme aponta o Dossiê Urbano Habitacional e Ambiental de Arapiraca (PREFEITURA MUNICIPAL DE ARAPIRACA, 2004). No entanto, as principais praças ${ }^{5}$ do centro da cidade, denominadas Praças Luiz Pereira Lima, Deputado Marques da Silva e Manoel André são

\footnotetext{
${ }^{5}$ Embora existam outras praças no centro de Arapiraca, este estudo se concentrou somente em três delas devido aos seus significados e representatividade para a cidade. Todavia, não foi objetivo do presente trabalho realizar possíveis comparações.
}

exemplos de alguns espaços públicos que apresentam cobertura arbórea significativa, o que, entre outros fatores, tornou-se um elemento relevante para esta análise (Figura 2).

Figura 2. Detalhe da planta do bairro centro, sem escala. O retângulo vermelho representa a delimitação da Praça Manoel André, o azul a Praça Deputado Marques da Silva e o preto a Praça Luiz Pereira Lima

Figure 2. Detail of the center neighborhood plan, no scale. Red rectangle represents the boundary of Manoel Andrew Square, blue one Marques da Silva Square and the black one Deputado Luiz Pereira Lima Square

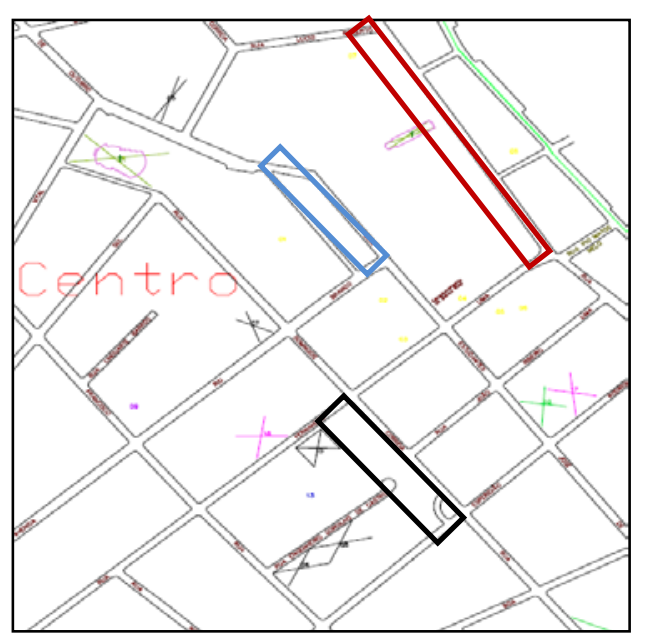

Fonte: Extraída do mapa do perímetro e divisão de bairros (PREFEITURA MUNICIPAL DE ARAPIRACA, 2007)

A Praça Luiz Pereira Lima, historicamente conhecida na cidade como a Praça da Prefeitura, devido a antiga localização da sede da Prefeitura do Município, se apresentava até pouco tempo, como um dos espaços públicos centrais mais carentes em infraestrutura, pois ao longo de anos tornou-se um local “esquecido” pela gestão pública. Contudo, no ano de 2009, iniciou-se nessa praça uma reforma que durou cerca de dezoito meses, sendo inaugurada em outubro de 2010, conforme placa implantada no local e observações pessoais. Com essa reforma, o local passou a ser mais frequentado, o que não ocorria anteriormente devido aos poucos atrativos. Apesar de algumas mudanças importantes, as árvores presentes nesse local foram conservadas, sendo acrescentados apenas alguns estratos arbustivos, flores e CARACTERIZAÇÃO E ANÁLISE QUALI-QUANTITATIVA... 
gramado para o embelezamento, além de 7 exemplares juvenis de Bauhinia sp.

Quanto aos seus equipamentos, estes foram modificados após a reforma, como playgrounds e estruturas esportivas que cederam lugar para uma grande tenda utilizada em eventos. A praça permite somente o uso contemplativo ou o convívio social. Com o término das obras foi possível notar que seu projeto paisagístico compartilha muitas semelhanças com outros espaços públicos, ou seja, está havendo uma padronização desses espaços em Arapiraca.

A Praça Deputado Marques da Silva, inaugurada em 28 de maio de 1994, segundo placa no local, tornou-se ao longo de anos um dos locais de intenso fluxo diário de pessoas devido às diversas casas comerciais nas imediações, além de lanchonete, banca de revistas e floricultura em seu espaço interno. Embora seja uma das principais praças da cidade devido ao comércio e localização estratégica, é um local com pouco tratamento estético-paisagístico, pois apesar de possuir uma boa cobertura arbórea, esta precisa de uma manutenção mais eficaz e períodica.

Quanto aos equipamentos urbanos, a praça apresentou somente bancos cobertos pela arborização. Seus usos não permitem a cessão de espaço para alocação de equipamentos diversos, como briquedos para crianças, estruturas esportivas e outros.

A Praça Manoel André, núcleo de origem da cidade de Arapiraca, denominada em 1910 de Praça Gabino Bezouro, segundo o Plano Diretor Participativo de Arapiraca (PREFEITURA MUNICIPAL DE ARAPIRACA, 2005), também localiza-se em uma área de intensa circulação de pessoas devido às casas comerciais do entorno. Há alguns anos essa praça foi reformada, culminando nas características atuais. Nota-se uma área relativamente extensa em comprimento, mas estreita em largura, o que impede determinados usos. Trata-se de um dos poucos espaços públicos que recebe tratamento paisagístico e manutenção periódica, apesar desses cuidados não se estenderem a sua arborização.

No que se refere aos equipamentos, se aplica a esta praça o mesmo fato que ocorre com a Praça Deputado Marques da Silva, situada na circunvizinhança. Seu espaço interno também foi ocupado por lanchonetes e banca de revistas.

\section{Coleta e análise de dados}

Para a caracterização da arborização destas praças supracitadas, foram realizadas visitas de campo, em novembro de 2010. Em cada local foi realizada a catalogação das árvores com base no critério de percorrer o local de acordo com a metodologia de cobertura do setor adotada pelo IBGE no Censo Demográfico 2010b. Ou seja, foi realizado o levantamento quantitativo e qualitativo de todos os indivíduos de hábito arbóreo encontrados no caminho percorrido de forma ordenada e disciplinada mantendo-se a árvore a ser recenseada sempre à direita para impedir contagens duplas, tornandose desnecessária a colocação de placas para enumerar os indíviduos, tendo em vista a pequena extensão das praças e a disposição das árvores, em geral. Antes de percorrer a área, foi marcado um ponto de partida inicial representado pela interseção de ruas ou pontos de referências facilitando, por exemplo, o retorno a árvore, caso fosse necessário.

Além disso, foi preenchido um formulário qualiquantitativo específico; coletou-se os elementos vegetais, como frutos, folhas e flores na forma de exsicatas (exemplar/estrutura botânico dessecado) e fotografou-se com câmera digital os indivíduos para auxiliar na identificação e observação de suas condições gerais de fitossanidade.

Para a coleta e o armazenamento do material botânico foram utilizados tesoura de poda de $3 \mathrm{~m}$ de altura, prensas de madeira, jornais novos, papelões, corrugado de metal (pedaço de uma placa de alumínio ou ferro), cordão para amarrar a prensa com as exsicatas confeccionadas, além de uma estufa para secagem do material. Na produção das exsicatas, após a coleta do material botânico, utilizou-se uma ficha de coleta com 
informações que auxiliasse a caracterização da árvore, sua identificação e localização no espaço público. O material botânico coletado foi identificado no Laboratório de Biologia da Universidade Federal de Alagoas-Campus Arapiraca.

As identificações das espécies foram realizadas através de bibliografia especializada (SOUZA; LORENZI, 2005; GONÇALVES; LORENZI, 2007) e morfologia comparada, em laboratório com o auxílio de lupa e análises de exsicatas e fotografias. Para consultar os nomes científicos das espécies foram observados o Sistema de Classificação do APG II (SOUZA; LORENZI, 2005) e o site do Centro Nordestino de Informações sobre Plantas (CNIP). Mesmo assim, não foi possível identificar todas as espécies de árvores devido à ausência de estruturas, como flores e frutos.

Para interpretar alguns dados relativos às espécies encontradas nas três praças foram utilizados os índices de frequência relativa e de diversidade $(\alpha)$, apontados por Rocha et al. (2004) e Rossato et al. (2008), respectivamente. O primeiro índice foi calculado através da razão entre o número de indivíduos de determinada espécie e o número total de indivíduos de toda a praça multiplicado por 100; o segundo, refere-se à taxa de heterogeneidade das espécies, onde os valores inferiores a 2,0 são considerados como indicativos de praças com baixa diversidade e valores superiores a 5,0 são considerados como indicativos de grande diversidade. Logo, acredita-se que as taxas intermediárias desses valores podem indicar que as praças possuem uma diversidade de espécies média ou significativa. Esses índices foram organizados para este estudo e foram representados por fórmulas matemáticas simples.

\section{Levantamento qualitativo das espécies arbóreas}

Para organizar os dados, durante as visitas de campo foi utilizado o formulário quali-quantitativo adaptado para contemplar os objetivos deste trabalho. O formulário original foi elaborado por Silva Filho (2002) quando analisou a arborização das vias públicas da área urbana do município de Jaboticabal-SP.

Este formulário registrou informações, como o nome e o endereço da praça; o número do indivíduo observado; os aspectos biológicos de cada exemplar; a existência de conflitos da arborização com fiações elétricas, iluminação e sinalização públicas, além da pavimentação e a ocorrência de podas nas árvores. Durante o trabalho de campo foi difícil identificar o tipo preciso de poda praticado, por isso o formulário contemplou apenas o tipo provável de poda adotado, conforme a percepção da pesquisadora.

Os aspectos biológicos foram representados por: estado geral/conservação do indivíduo, representado por ótimo (indivíduo vigoroso e sadio, sem sinais de ataque de “pragas”, doenças ou injúrias mecânicas), bom (indivíduo com algum sinal de deficiência superficial, ataque de “pragas”, doenças, ou injúria mecânica superficial), regular (indivíduo em início de declínio, podendo apresentar ataque de "pragas", doenças, ou injúrias mecânicas, que descaracterizem sua arquitetura ou resultem em deficiências) e péssimo (indivíduo em estado avançado de declínio, com ataque ou dano intenso de “pragas” ou doenças, resultando em risco de queda ou morte do vegetal); aspectos fitossanitários (verificou-se a presença de cupins, formigas, lagartas, fungos e outros fitopatógenos); intensidade do ataque (leve, média e pesada); local do ataque (caule, raiz, frutos, flores e folhas); injúrias/danos mecânicos (intensidade grave, média e leve, tendo como exemplos casos de vandalismos) e ecologia (observou-se a presença de insetos não fitopatogênicos, ninhos de passeriformes e líquens).

CARACTERIZAÇÃO E ANÁLISE QUALI-QUANTITATIVA... 


\section{RESULTADOS E DISCUSSÕES}

A Praça Luiz Pereira Lima apresentou 32 árvores, a Praça Deputado Marques da Silva 16 e a Praça Manoel André 17, totalizando 65 árvores, o que apontou para uma distribuição irregular da cobertura arbórea em áreas específicas da cidade, mesmo considerando as diferenças de extensão desses espaços. As árvores destas três praças foram distribuídas em 9 espécies, 11 gêneros e 9 famílias botânicas. No entanto, quatro espécies representaram 50,8\% das árvores cultivadas nesses espaços públicos (Pachira aquatica Aubl., Caesalpinia echinata Lam., Schinus terebinthifolius Raddi e Erythrina indica Lam.). As espécies de maior frequência relativa foram: Pachira aquatica (27,7\%), Erythrina indica (10,8\%), Schinus terebinthifolius (7,7\%) e Caesalpinia echinata (4,6\%).

Os resultados obtidos corroboram com os dados registrados por Rezende e Santos (2010) quando analisaram as praças do bairro Jaraguá em UberlândiaMG, pois constataram 196 indivíduos arbóreos distribuídos por 21 espécies, sendo que cinco delas representavam 72,94\% das árvores contabilizadas.

A tabela 1 mostra as espécies e as famílias botânicas encontradas nas três praças analisadas no presente estudo, bem como expõe alguns gêneros e os indivíduos indeterminados.

Tabela 1. Espécies arbóreas e famílias botânicas encontradas nas Praças Luiz Pereira Lima (PLPL), Deputado Marques da Silva (PDMS) e Manoel André (PMA) em Arapiraca/AL

Table 1. Tree species and plant families found in Squares Luiz Pereira Lima (PLPL), Deputado Marques da Silva (PDMS) and Manoel André (PMA) in Arapiraca

\begin{tabular}{|c|c|c|c|c|c|}
\hline Espécies arbóreas & Nome popular & Família & PLPL & PDMS & PMA \\
\hline Terminalia catappa L. & Amendoeira & Combretaceae & $\bar{X}$ & & - \\
\hline Schinus terebinthifolia Raddi & Aroeira & Anacardiaceae & $\mathrm{X}$ & $\bar{X}$ & $\bar{X}$ \\
\hline Erythrina indica Lam. & Brasileirinho & Fabaceae & $\mathrm{X}$ & _- & $\mathrm{X}$ \\
\hline Caesalpinia echinata L. & Pau-brasil & Fabaceae & - & $\bar{X}$ & $\mathrm{X}$ \\
\hline Sapindus saponaria L. & Sabonete & Sapindaceae & $\bar{X}$ & _- & - \\
\hline Pachira aquatica Aubl. & Monguba & Malvaceae & $\mathrm{X}$ & $\bar{X}$ & - \\
\hline Tabebuia aurea (Silva Manso) & Craibeira/ipê & Bignoniaceae & _- & $\mathrm{X}$ & - \\
\hline \multicolumn{6}{|l|}{ Benth. e Hook. f. ex S. Moore } \\
\hline Ficus benjamina L. & Figueira & Moraceae & & $\mathrm{X}$ & \\
\hline Azadirachta indica A. Juss. & Nim & Meliaceae & _ & _- & $\mathrm{X}$ \\
\hline Bauhinia sp & & Fabaceae & - & - & $\mathrm{X}$ \\
\hline Tabebuia sp & Ipê & Bignoniaceae & X & - & _- \\
\hline Enterolobium $s p$ & & Fabaceae & $\mathrm{X}$ & - & - \\
\hline Indeterminada I & Palmeira & Arecaceae & $\mathrm{X}$ & - & - \\
\hline Indeterminada II & _ & _- & $\mathrm{X}$ & - & - \\
\hline Indeterminada III & Palmeira & Arecaceae & _ & $\bar{X}$ & - \\
\hline Indeterminada IV & _ & _ & - & $\mathrm{X}$ & \\
\hline Indeterminada V & & & - & _- & $\mathrm{X}$ \\
\hline
\end{tabular}

As famílias mais frequentes foram representadas por: Malvaceae (27,7\%), Fabaceae (26,2\%), Arecaceae $(15,4 \%)$ e Anacardiaceae (7,7\%). As demais famílias apresentaram frequências entre 1,5\% (Sapindaceae,
Meliaceae e Moraceae) e 3,1\% (Combretaceae e Bignoniaceae).

Embora a frequência de Malvaceae tenha sido maior, este índice foi representado somente por uma espécie 
(Pachira aquatica), o mesmo ocorreu com uma espécie da família Anacardiaceae (Schinus terebinthifolia). A família Fabaceae apresentou maior diferenciação de gêneros, isto é, quatro. Ao calcular-se o índice de diversidade na arborização das praças, observou-se que existem 4,4 espécies diferentes em cada espaço. Por outro lado, quando consideradas as praças de forma individual, o maior índice de diversidade de espécies encontrou-se na Praça Deputado Marques da Silva $(3,3)$ e o menor, na Praça Manoel André $(2,4)$. A Praça Luiz Pereira Lima apresentou um índice de 2,6. Coadunadas as praças possuem uma diversidade arbórea significativa, porém, quando analisadas de modo comparativo e individual tendem a apresentar índices baixos de diversidade.

Este fato foi comprovado quando se percebeu que $37,5 \%$ do acervo arbóreo da Praça Luiz Pereira Lima era composto pela espécie Pachira aquatica; o da Praça Deputado Marques da Silva também de Pachira aquatica $(37,5 \%)$ e de Schinus terebinthifolius (12,5\%) e o da Praça Manoel André de árvores da espécie Erythrina indica (35,3\%). Para Brun et al. (2007) um dos fatores que podem comprometer a arborização nas cidades consiste no cultivo de poucas espécies e de forma descontínua, resultando na perda de biodiversidade.

A literatura comumente aborda que cultivar muitas árvores de uma mesma espécie pode aumentar a disseminação de certos fitopatógenos, pois se alguns exemplares forem atacados por cochonilhas e/ou pulgões, que migram devido a algumas condições ambientais, pode prejudicar muitas árvores. Por isso, não se aconselha a homogeneidade ou uniformização da paisagem, como afirmam Rodolfo Júnior et al. (2008), Machado et al. (2006) e Yamamoto et al. (2004). Além da questão fitossanitária, com um grande número de indivíduos iguais em uma praça, acredita-se que, esteticamente, elas tornam o local pouco harmonioso e/ou atrativo para a contemplação.

Estudos, como os citados, abordam que em muitas cidades do Brasil é uma prática comum o cultivo de poucas espécies para compor a arborização, o que não deveria ocorrer tendo em vista os inúmeros prejuízos que podem desencadear.
Para proteger a arborização contra "pragas" e doenças, Santamour Júnior (2002) recomenda que não se deve exceder mais que $10 \%$ de uma mesma espécie ou $30 \%$ de uma mesma família botânica em determinados locais. Para Milano e Dalcin (2000) tem-se um limite maior de tolerância de espécies, pois aconselham não ultrapassar 10\% a 15\% de ocorrência de uma mesma espécie.

Diante desses índices, observou-se que na Praça Deputado Marques da Silva a espécie Pachira aquatica ultrapassou os valores recomendados, mas quanto a espécie Schinus terebinthifolia, estava no limite tolerável; na Praça Luiz Pereira Lima a espécie Pachira aquatica também ultrapassou os valores e na Praça Manoel André a espécie Erythrina indica não obedeceu os índices recomendados. Quanto à ocorrência de famílias, verificou-se que nenhuma excedeu os $30 \%$ recomendado por Santamour Júnior (2002), indicando uma diversidade considerável em todas as praças no que se refere à família botânica. Todavia, a alta concentração de indivíduos de Pachira aquatica em duas das três praças, sugeriu a necessidade de se refletir sobre os cuidados quanto a fitossanidade de seus exemplares, pois o ataque de um fitopatógeno poderia dizimar uma grande quantidade de indivíduos.

Analisando a origem das 9 espécies identificadas nas três praças, percebeu-se que 4 são típicas da Região Nordeste do Brasil (Tabebuia aurea, Schinus terebinthifolia, Caesalpinia echinata e Sapindus saponaria), de acordo com a Lista de Checagem das Plantas do Nordeste Brasileiro do CNIP (2011), especialmente das formações vegetais encontradas no município de Arapiraca-AL (Caatinga e Mata Atlântica). Este resultado divergiu dos encontrados em outras cidades da Região Nordeste. Calixto Júnior et al. (2009) registraram em Lavras da Mangabeira-CE uma prevalência de espécies exóticas sobre as nativas, Machado et al. (2006) encontraram na cidade de Teresina-PI um predomínio de espécies exóticas na arborização, Matos et al. (2010) e Santos et al. (2011) também verificaram na cidade de Aracaju-SE uma grande quantidade de espécies exóticas em detrimento das nativas, cada vez mais difíceis de serem notadas. 
Quanto as espécies Ficus benjamina L. e Azadirachta indica A. Juss. são comumente tratadas como potenciais causadoras de prejuízos na infraestrutura das cidades, devido a fatores limitantes, como o sistema de enraizamento, o porte pouco apropriado para certos locais ou a presença de fitopatógenos específicos. No que tange a espécie Pachira aquatica, esta pode não ser ideal para a arborização de espaços públicos, pois embora apresente potencialidades devido às características de sua copa densa, seus frutos relativamente grandes são considerados um problema para os usuários desses locais. Durante o processo de abscisão, os frutos podem atingir pessoas e veículos, causado prejuízos.

No que se refere às espécies Erythrina indica e Terminalia catappa L. existe pouca literatura confiável sobre suas características de crescimento e desenvolvimento. Considerá-las como originárias de outros países não foi suficiente para classificá-las como nativas ou exóticas da região de Arapiraca.

Quanto ao levantamento das características fitossanitárias das árvores, ou seu estado de conservação, nas três praças notou-se um acervo arbóreo: regular (41,5\%), péssimo (38,5\%), bom (17,0\%) e ótimo (3,0\%). Esses percentuais podem ter resultado da existência de 73,8\% de formigas; $61,5 \%$ de fungos; $15,0 \%$ de cupins e $9,2 \%$ de outros organismos potencialmente fitopatogênicos. As intensidades registradas destes ataques foram: 55,4\% média, 37,0\% leve e 7,7\% pesada. Os ataques foram preferencialmente no caule $(97,0 \%)$ e nas folhas $(3,0 \%)$. Apesar da diversidade dos percentuais das categorias que representam as condições gerais das árvores, percebeu-se nas categorias regular e péssimo uma quantidade elevada de indivíduos comprometidos (80,0\%). Esses dados divergem dos obtidos por Rodolfo Júnior et al. (2008), quando avaliaram as condições das árvores urbanas em bairros da cidade de Pombal-PB, pois registraram cerca de 40,0 a 50,0\% da arborização em bom estado de fitossanidade. Dessa forma, considerou-se a arborização das praças analisadas no presente trabalho insatisfatória (Figura 3A e 3B). Por outro lado, tais índices podem ser justificados pelas condições ambientais da região de
Arapiraca, como clima, pluvisiosidade, localização geográfica, temperatura, tipo de solo, entre outros.

A diversidade e o elevado percentual de diferentes organismos, potencialmente causadores de doenças nas árvores das praças, assinalaram a necessidade de medidas urgentes de controle desses organismos, pois podem promover, entre outros prejuízos, a morte do vegetal. Este fato pode ser agravado ao se verificar a intensidade do ataque dos organismos, pois mais da metade das árvores teve ataques de intensidades média e pesada $(63,1 \%)$, sobretudo na estrutura de sustentação do vegetal, o caule/tronco. Ainda foi percebida a presença de outros insetos, como abelhas, moscas e maribondos em 15,4\% das árvores, além de 12,3\% de líquens (associação de algas e fungos), estes geralmente relacionados à qualidade ambiental. Contudo, Raven et al. (2001) ressaltam que os líquens podem viver nos ambientes mais inóspitos da Terra e, consequentemente, são amplamente distribuídos, além de poderem atuar como substrato para fungos parasitas. Logo, é necessária cautela ao afirmar que a presença de líquens pode ser um parâmetro suficiente para classificar a arborização de um dado local como saudável. Além disso, constatou-se a ocorrência de injúrias ou agressões mecânicas praticadas contra as árvores, em 52,3\% dos casos. As intensidades dessas agressões foram avaliadas: 30,8\% média e 26,2\% leve (Figura 4A).

Sobre esta questão, Matos et al. (2010) afirmam que as árvores que emolduram as praças urbanas são vítimas eminentes nos períodos festivos, tendo em vista que comumente são utilizadas como suporte para ornamentação, o que demanda o uso de instrumentos de fixação dos adornos, como pregos e grampos. Estes, em geral, são esquecidos nas árvores após o evento, podendo causar sérios danos à saúde do vegetal. Outro tipo de agressão muito comum, constatado nas Praças Luiz Pereira Lima e Deputado Marques da Silva, foi a caiação ou pintura com cal dos troncos das árvores. A cal é um produto tóxico que pode prejudicar a vitalidade das árvores, por isso, deve ser uma prática abolida em Arapiraca (Figura 4B). 
Figura 3. Em A, notam-se insetos, popularmente, conhecidos como pulgões, cochonilhas e soldadinhos (ordem Homoptera) em um exemplar de Bauhinia sp, na Praça Manoel André. Em B, tem-se o detalhe de um caule comprometido, também na Praça Manoel André

Figure 3. In A, we note insects, popularly known as aphids, mealybugs (order Homoptera) in a sample of Bauhinia sp., at Praça Manoel André. In B, there is a detail from a committed stem, also in Manoel André Square
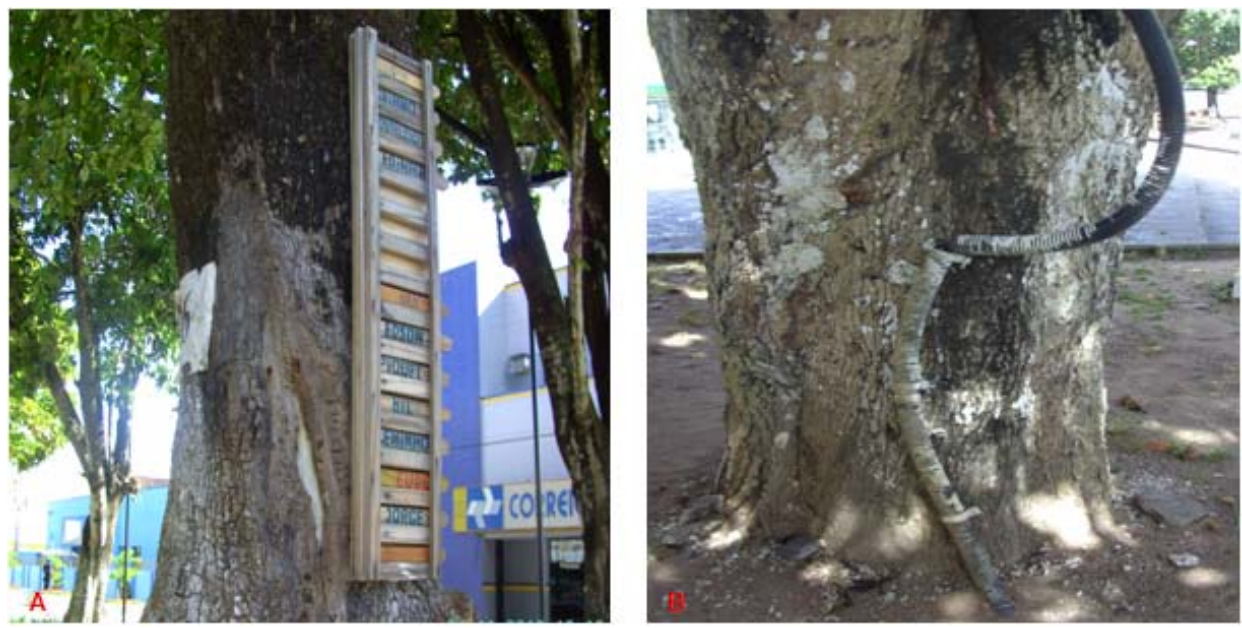

Foto: Carla C. F. Pessoa.

Figura 4. Em A, percebe-se um caule de Terminalia catappa L. com uma placa de madeira afixada, utilizada pelos mototaxistas que trabalham na Praça Luiz Pereira Lima. Em B, observa-se o tronco de uma Pachira aquatica Aubl. com um sistema de fiação elétrica e indícios de caiação na Praça Deputado Marques da Silva

Figure 4. In A, we find a stem of Terminalia catappa L. with a wooden board attached, used by mototaxi drivers working in the Luiz Pereira Lima Square. In B, there is the trunk of a Pachira aquatica Aubl. with an electrical wiring system and traces of whitewash in Deputado Marques da Silva Square

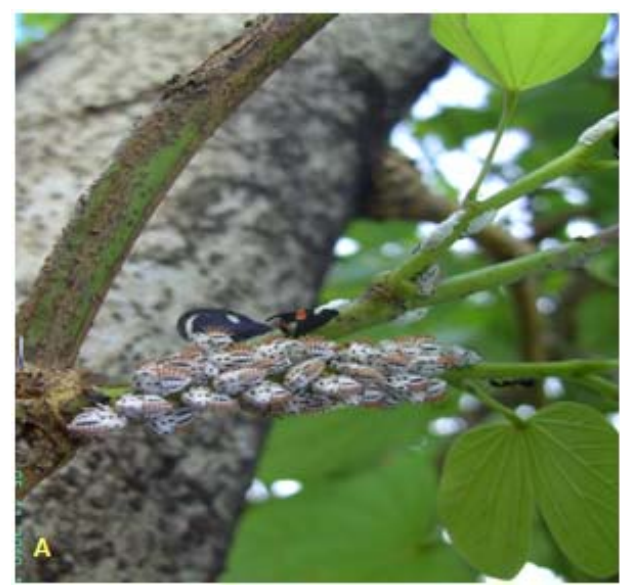

Outros parâmetros avaliados nas praças foram a existência de problemas entre a arborização e os equipamentos urbanos. A partir do diagnóstico de todas as árvores das três praças, foram registrados 35,4\% de conflitos da arborização com a iluminação pública, 1,5\% com a fiação elétrica e 1,5\% com a pavimentação, isto é, não foi constatado nenhum problema envolvendo as

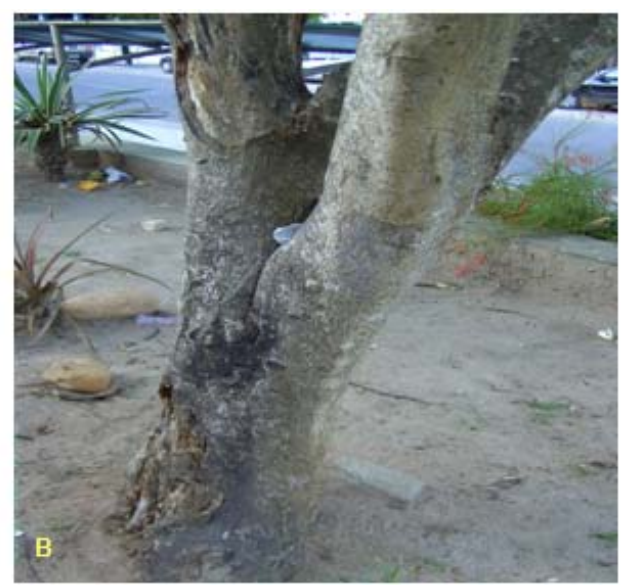

Foto: Carla C. F. Pessoa árvores e a sinalização nas praças. Menos da metade das árvores $(38,4 \%)$ das três praças apresentaram algum tipo de problema com equipamentos urbanos.

Os índices reduzidos de conflitos com a fiação e a pavimentação podem resultar da elevada ocorrência de podas na arborização das praças. Registrou-se que $80 \%$ das árvores costumam sofrer essa prática que, dentre

CARACTERIZAÇÃO E ANÁLISE QUALI-QUANTITATIVA... 
outras funções, pode promover alterações morfológicas durante o desenvolvimento ou estabelecimento da planta. A alta frequência de podas pode ser um indicativo de seleção inadequada de espécies para os locais (ANDRADE et al., 2008).

A poda é tratada pela literatura como uma das mais representativas formas de agressão às árvores urbanas, porém para Schallenberger et al. (2010) a poda significa um trato cultural, assim como o controle de "pragas” e doenças. Este tipo de tratamento pode ser benéfico para as árvores, no entanto, a prática de podar pode torna-se perigosa se realizada por pessoas não especializadas. Este fato tende a ser mais comum à medida que se percebe 0 crescente descaso na elaboração de políticas de controle e de tratamento fitossanitários, resultando muitas vezes em uma atitude "desesperada" e inadequada de moradores e gestores públicos com pouca informação e instrução sobre arborização urbana. Poucas foram as ocasiões em que a poda contribuiu com o desenvolvimento do vegetal, como nos casos de retirada de galhos doentes, mortos e/ou deformados, o que ocorreu com as podas de manuntenção ou de limpeza.

\section{CONSIDERAÇÕES FINAIS}

Com os resultados deste estudo, verificou-se que os problemas encontrados na arborização das praças evidenciam a ausência de políticas públicas de planejamento e manejo. Não se conhece em ArapiracaAL leis e/ou códigos específicos para tal finalidade, como a implantação de um Plano Diretor de Arborização Urbana. Como reflexo dessa situação, a arborização homogênea das praças apresentou vários organismos fitopagênicos, injúrias mecânicas, alguns conflitos com equipamentos urbanos, práticas inadequadas de poda e caiação de troncos.

Quanto ao caráter quantitativo da arborização, teve-se um número reduzido de exemplares arbóreos nas três praças. Todavia, a arborização desses locais têm funções e significados distintos de outros espaços públicos na cidade. Em relação à identificação das espécies, quatro destas foram consideradas nativas do Nordeste do Brasil, o que significou um fato importante para arborização.
Esperou-se com esta análise contribuir com o planejamento e gestão da arborização das praças de Arapiraca e também de outras cidades que apresentem problemática semelhante. Arborizar determinada área não significa apenas plantar árvores, mas requer a necessidade de investimentos em cuidados periódicos para que estes organismos vivos resultem nos benefícios esperados e melhorem a sensação de artificialização do ambiente. Devem-se priorizar ações de controle fitossanitário, de distribuição regular das espécies e de sua diversidade. Além disso, recomendou-se a criação e implantação de um Plano de Manejo e de Monitoramento da Arborização, dentre outras medidas pontuais que visem a melhoria e a ampliação do quantitativo arbóreo e das potencialidades das árvores na cidade de Arapiraca.

\section{AGRADECIMENTOS}

A autora agradece aos revisores deste artigo pela contribuição visando a melhoria do mesmo e, sobretudo ao professor Marcos Antônio Silvestre Gomes da Universidade Federal Fluminense (UFF) pela correção do texto e orientação. Também agradece ao professor
Henrique Costa Hermenegido da Silva pelo auxílio na identificação das espécies, bem como à graduanda em Biologia, Carla Caroline Felício Pessoa, pela colaboração na coleta do material botânico, ambos da Univesidade Federal de Alagoas-Campus Arapiraca. 


\section{REFERÊNCIAS BIBLIOGRÁFICAS}

AMORIM, V. P. Aspectos práticos da tecnologia de saneamento básico. Roteiro Editorial Ltda, 2005.

ANDRADE, C. C.; RAPHAEL, M.; CARDOSO, A. L.; ROCHA, M. J. R.; LOPES, T. S.; SILVA, A. G. Inventário da arborização viária da cidade de Jerônimo Monteiro-ES. In: XII ENCONTRO LATINO AMERICANO DE INICIAÇÃO CIENTÍFICA E VIII ENCONTRO LATINO AMERICANO DE PÓS-GRADUAÇÃO, 12., 2008, São José dos Campos. Anais..., 2008, p. 1-3. <http://www.inicepg.univap.br>. Acesso em: 17 jan. 2011.

BATISTEL, L. M.; DIAS, M. A. B.; MARTINS, A. S.; RESENDE, I. L. M. Diagnóstico qualitativo e quantitativo da arborização urbana nos bairros Promissão e Pedro Cardoso, Quirinópolis, Goiás. Rev. da Sociedade Brasileira de Arborização Urbana, Piracicaba, v. 4, n.3, p. 110-129, ago. 2009.

BRUN, F. G. K.; LINK, D.; BRUN, E. J. O emprego da arborização na manutenção da biodiversidade de fauna em áreas urbanas. Rev. da Sociedade Brasileira de Arborização Urbana, Piracicaba, v. 2, n.1, p. 117-127, 2007.

CALIXTO JÚNIOR, J. T.; SANTANA, G. M.; LIRA FILHO, J. A. Análise quantitativa da arborização urbana de Lavras da Mangabeira, CE, Nordeste do Brasil. Rev. da Sociedade Brasileira de Arborização Urbana, Piracicaba, v. 4, n. 3, p. 99109, ago. 2009.

CAVALHEIRO, F.; DEL PICCHIA, P. C. D. Áreas verdes: conceitos, objetivos e diretrizes para o planejamento. In: I CONGRESSO BRASILEIRO SOBRE ARBORIZAÇÃO URBANA E IV ENCONTRO NACIONAL SOBRE ARBORIZAÇÃO URBANA, 1992, Vitória. Anais... Vitória, 1992, p. 29-38.

CENTRO NORDESTINO DE INFORMAÇÕES SOBRE PLANTAS (CNIP). Checklist das plantas do Nordeste brasileiro: Angiospermae e Gymnospermae. Disponível em: <http://www.cnip.org.br>. Acesso em: 05 jan. 2011.

FERNANDES, A. M. V. O reencantamento (mercadológico) pela natureza e a segregação socioespacial na APA de Sousas e Joaquim Egídio (Campinas/SP). In: XV ENCONTRO NACIONAL DE GEÓGRAFOS: O ESPAÇO NÃO PÁRA. POR UMA AGB EM MOVIMENTO, 15., 2008, São Paulo. Anais... São Paulo, 2008.

GOMES, M. A. S.; AMORIM, M. C. C. T. Arborização e conforto térmico no espaço urbano: estudo de caso nas praças públicas de presidente prudente (SP). Rev. Caminhos de Geografia, Uberlândia, v. 7, n. 10, p. 94-106, set. 2003.

GONÇALVES, E. G.; LORENZI, H. Morfologia vegetal: organografia e dicionário ilustrado de morfologia das plantas vasculares. Nova Odessa: Instituto Plantarum, 2007. 306p.

INSTITUTO BRASILEIRO DE GEOGRAFIA E ESTATÍSTICA (IBGE). Censo Demográfico 2010: manual do recenseador. Ministério do Planejamento, Orçamento e Gestão. Rio de Janeiro, 2010b. 332p.

Acesso em: 05 jan. 2011.

Primeiros resultados do Censo Demográfico 2010a. Disponível em: <http://www.ibge.gov.br>.

JARDIM BOTÂNICO DO RIO DE JANEIRO. Lista de espécies da flora do Brasil. Disponível em: <http://floradobrasil.jbrj.gov.br>. Acesso em: 6 maio 2011.

LIMA, A. M. L. P.; CAVAlHEIRO, F.; NUCCI, J. C.; SOUSA, M. A. L. B.; FIALHO, N. O.; DEL PICCHIA, P. C. D. Problemas de utilização na conceituação de termos como espaços livres, áreas verdes e correlatos. In: II CONGRESSO BRASILEIRO DE ARBORIZAÇÃO URBANA, 2., 1994, São Luís. Anais... São Luís, 1994, p. 539-553.

LORENZI, H. Árvores brasileiras: manual de identificação e cultivo de plantas arbóreas nativas do Brasil. 3. ed. Nova Odessa: Instituto Plantarum, 2009. 384p.

. Árvores brasileiras: manual de identificação e cultivo de plantas arbóreas nativas do Brasil. 5. ed. Nova Odessa: Instituto Plantarum, 2008. 384p.

MACHADO, R. R. B.; MEUNIER, I. M. J.; SILVA, J. A. A.; CASTRO, A. A. J. F. Árvores nativas para arborização de Teresina-Piauí. Rev. da Sociedade Brasileira de Arborização Urbana, Piracicaba, v. 1, n. 1, p. 10-18, 2006. 
MASCAREnHAS, J. C.; BELTRÃO, B. A.; SOUZA JÚNIOR, L. C. (Org.). Projeto cadastro de fontes de abastecimento por água subterrânea: diagnóstico do município de Arapiraca, Estado de Alagoas. Ministério de Minas e Energia. Secretaria de Geologia, Mineração e Transformação Mineral. Recife: CPRM/PRODEEM, 2005. 13p.

MATOS, E. C. A.; NASCIMENTO-JÚNIOR, J. E.; MARIANO, D. L. S.; OLIVEIRA, A. L. Arborização do bairro Centro da cidade de Aracaju, Sergipe, e seus organismos associados. Rev. da Sociedade Brasileira de Arborização Urbana, Piracicaba, v. 5, n. 4, p. 22-39, dez. 2010.

MILANO, M.; DALCIN, E. Arborização de vias públicas. Rio de Janeiro: Light, 2000. 226p.

MIRANDA, T. O.; CARVALHO, S. M. Levantamento quantitativo e qualitativo de indivíduos arbóreos presentes nas vias do bairro da Ronda e Ponta Grossa-PR. Rev. da Sociedade Brasileira de Arborização Urbana, Piracicaba, v. 4, n.3, p. 143157 , set. 2009.

NUCCI, J. C. Qualidade ambiental e adensamento urbano. São Paulo: Humanitas/FAPESP, 2001. 236p.

PREFEITURA MUNICIPAL DE ARAPIRACA. Dossiê urbano habitacional e ambiental do Município de ArapiracaAL. Cooperativa de Trabalhadores Ambientalistas. Maceió, 2004. 257p.

Mapa de Arapiraca: perímetro e divisão de bairros. Arapiraca, 2007. Sem escala.

|

Plano Diretor Participativo do Município de Arapiraca. Diagnóstico_técnico-comunitário. Secretaria Municipal de Desenvolvimento Urbano e Meio Ambiente. Arapiraca, 2005. 218p.

Relatório das características ambientais do município de Arapiraca-AL. Secretaria Municipal de Desenvolvimento Urbano e Meio Ambiente. Arapiraca, 2006. 99p.

RAVEN, P. H.; EVERT, R. F.; EICHHORN, S. E. Biologia vegetal. 6. ed. Rio de Janeiro: Guanabara Koogan, 2001. 906p.

REZENDE, T. M.; SANTOS, D. G. Avaliação quali-quantitativa da arborização das praças do bairro Jaraguá, UberlândiaMG. Rev. da Sociedade Brasileira de Arborização Urbana, Piracicaba, v. 5, n. 2, p. 139-157, jun. 2010

ROCHA, J. R.; WERLANG, M. K. Índice de cobertura vegetal em Santa Maria: o caso do Bairro Centro. Rev. Ciência e Natura, Santa Maria, v. 27, n. 2, p. 85-99, 2005.

ROCHA, R. T.; LELES, P. S. S.; OLIVEIRA NETO, S. N. Arborização de vias públicas em Nova Iguaçu: o caso dos bairros Rancho Novo e Centro. Revista Árvore. Viçosa, v.28, n.4, p. 599-607, jul./ago. 2004.

RODOLFO-JÚNIOR, F.; MELO, R. R.; CUNHA, T. A.; STANGERLIN, D. M. Análise da arborização urbana em bairros da cidade de Pombal no Estado da Paraíba. Rev. da Sociedade Brasileira de Arborização Urbana, Piracicaba, v. 3, n. 4, p. 319, out. 2008.

RODRIGUES, A. M. Problemática Ambiental = Agenda Política - Espaço, território, classes sociais. Boletim Paulista de Geografia - "Perspectiva Crítica”, São Paulo, n. 83, p. 91-100, dez. 2005.

ROMÃO, S. R. L. A cidade do futuro: agenda 21 Arapiraca. Maceió: Ideário Comunicação e Cultura, 2008. 171p.

ROSSATO, D. R; TSUBOY, M. S. F; FREI, FERNANDO. Arborização urbana na cidade de Assis-SP: uma abordagem quantitativa. Rev. da Sociedade Brasileira de Arborização Urbana, Piracicaba, v. 3, n. 3, p. 1-16, dez. 2008.

SANTAMOUR JÚNIOR, F. S. Trees for urban planting: diversity uniformity, and common sense. Agriculture Research Service. Washington: U. S. National Arboretum, 2002.

SANTOS, C. Z. A.; FERREIRA, R. A.; SANTOS, L. R.; SANTOS, L. I.; GRAÇA, D. A. S.; GOMES, S. H.; PORTO NETO, W. B.; CORREIA, T. S.; BOSCHESE, A. C. B. Composição florística de 25 vias públicas de Aracaju-SE. Rev. da Sociedade Brasileira de Arborização Urbana, Piracicaba, v. 6, n. 2, p. 125-144, jul. 2011.

SCHALLENBERGER, L. S.; ARAÚJO, A. J.; ARAÚJO, M. N.; DEINER, L. J.; MACHADO, G. O. Avaliação da condição de árvores urbanas nos principais parques e praças do município de Irati-PR. Rev. da Sociedade Brasileira de Arborização Urbana, Piracicaba, v. 5, n. 2, p. 105-123, jun. 2010. 
SILVA FILHO, D. F. Cadastramento informatizado, sistematização e análise da arborização das vias públicas da área urbana do município de Jaboticabal-SP. 2002. 81p. Dissertação (Mestrado). Universidade Estadual Paulista "Júlio de Mesquita Filho", Jaboticabal.

SILVA, G. C. Questões ambientais, culturais e socioeconômicas de espaços livres urbanos: praças do Centro da cidade de Teresina-PI. 2009. 172f. Dissertação (Mestrado em Desenvolvimento e Meio Ambiente). Universidade Federal do Piauí, Teresina.

SOUZA V. C.; LORENZI H. Botânica sistemática: guia ilustrado para identificação das famílias de angiospermas da flora brasileira, baseado em APG II. Nova Odessa: Instituto

Plantarum, 2005.

TARNOWSKI, L. C.; MOURA, R. O espaço do meio ambiente urbano no discurso ecológico. In: III ENCONTRO NACIONAL DE ESTUDOS SOBRE O MEIO AMBIENTE, 3., 1991, Londrina. Anais... Londrina: UEL/NEMA, 1991, p. 379-391.

YAMAMOTO, M. A.; SCHIMIDT, R. O. L.; COUTO, H. T. Z.; SILVA FILHO, D. F. Árvores Urbanas. Piracicaba, 2004. 18p. Disponível em: <http://lmq.esalq.usp.br>. Acesso em: 17 jan. 2011. 